\title{
Rudimentary horn pregnancy mimicking as a case of
} placenta accreta

Aruna Nigam, Manju Puri, Shubha Sagar Trivedi, Pikee Saxena

Department of Obstetrics and Gynaecology, Lady Hardinge Medical College,

New Delhi 110001 , India

\section{Abstract:}

Pregnancy in a rudimentary horn is very rare condition and it generally culminates in rupture, in second trimester with torrential haemorrhage. The accuracy of ultrasound in diagnosing rudimentary horn pregnancy at an advanced gestation still remains elusive. We report a case of unruptured rudimentary horn pregnancy which progressed to 38 weeks of gestation. The diagnosis was missed at 24,30 and 38 weeks of gestation on obstetric sonogram. The diagnosis was made at laparotomy when the patient was planned for caesarean section in view of placenta accreta.

Key words: Rudimentary horn pregnancy, placenta accreta, mullerian duct anomalies.

\section{Introduction}

Mullerian duct anomalies are infrequently encountered in day to day gynaecological practice. Septate uterus is the commonest uterine anomaly with a mean incidence of approximately $35 \%$ followed by bicornuate uterus (approximately $25 \%$ ) and arcuate uterus (approximately 20\%).[1] Pregnancy in a rudimentary horn is reported to be 1/40,000.[2] We present a rare case of unruptured term pregnancy in a rudimentary horn who presented to us as a case of placenta accreta.

\section{Case report}

A 26 years G2P1 LO at 38 weeks of gestation presented in the casualty with the complaints of loss of fetal movements for one week. Her last delivery was a full term vaginal delivery one year back. On admission her vitals were stable. Her per abdominal examination revealed enlarged uterus corresponding to 28 weeks pregnancy, with a single foetus in breech presentation with absent fetal heart sound and reduced liquor. Her ultrasound showed a single intrauterine fetus of 31 weeks 3 days gestation with hyperflexed spine and absent cardiac activity. The liquor was reduced and placenta was low lying covering the os with suspicion of placenta accreta which was confirmed on Doppler flow studies. She was planned for caesarean section in view of placenta previa and accreta. On opening the abdomen, uterus was normal in size with an enlarged rudimentary horn on right side. The pedicle of the horn was $3 \mathrm{~cm}$ broad attached to the right lateral side of the uterus extending from the fundus to the body of the uterus (Fig. 1). The left tube and the ovary were normal. The right tube, right ovarian and round ligaments were attached to the lateral side of the right rudimentary horn. The rudimentary horn with pregnancy insitu was excised. A dead macerated male baby weighing $1.5 \mathrm{~kg}$ was present in the right horn. The placenta was morbidly adherent to the base of the horn. As the pedicle of rudimentary horn was wide and the patient has no history of dysmenorrhoea, it was probably a communicating type of rudimentary horn. The postoperative period was uneventful. 


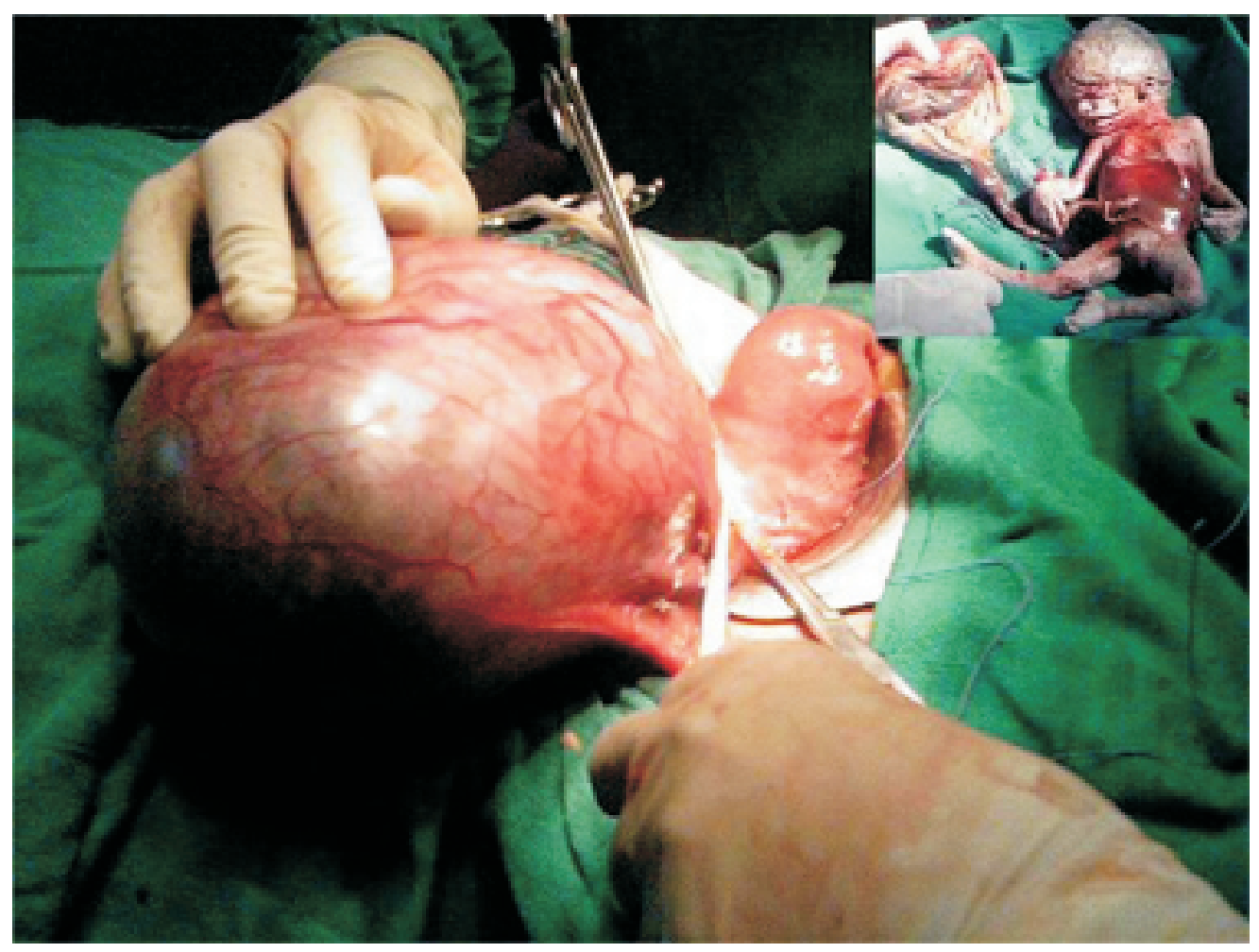

Figure 1: Enlarged rudimentary horn with pregnancy insitu and normal size uterus, inset showing excised rudimentary horn with placenta accreta and the fetus

\section{Discussion}

Pregnancy in a rudimentary horn is an uncommon and a potentially life threatening condition. It mostly terminates by rupture between 5 to 35 weeks of gestation depending on the musculature of the rudimentary horn and its ability to hypertrophy and distend. Majority (70\%-90\%) rupture before 20 weeks of gestation. As reported in literature only $5 \%$ of the reported cases were diagnosed preoperatively, the diagnosis was mostly made at laparotomy or laparoscopy.[3]

The accuracy of ultrasound in the diagnosis of rudimentary horn pregnancy is fairly good at an early gestation however it remains poor at an advanced gestation. The condition is usually suspected clinically in the first trimester by bimanual finding of a palpable mass extending outward from uterine angle (Baart de la faille"s sign) or displacement of fundus to contralateral side with rotation of uterus and elevation of the affected horn (Ruge Simon Syndrome).

There are very few cases, $[4,5]$ in the literature in which the rudimentary horn pregnancy continued till term. Our case is peculiar in a sense that it continued till 38 weeks without rupturing and was missed on serial ultrasonography in antenatal period. A high index of suspicion of rudimentary horn pregnancy should be kept in mind wherever the diagnosis of placenta accreta is made in a patient in the absence of any factor, predisposing to morbidly adherent placenta like previous lower segment caesarean section, dilation \& curettage etc. Early diagnosis of this rare form of pregnancy prior to rupture is essential for timely management in order to prevent associated maternal morbidity and mortality. The rudimentary horn should be excised whenever diagnosed. 


\section{References}

1. Grimbizis GF, Camus M, Tarlatzis BC, Bontis JN, Devroey P. Clinical implications of uterine malformation and hysteroscopic treatment results. Human Reprod Update. 2001; 7(2):161174.

2. Sfar E, Zine S, Bourghida S, Bettaieb A, Chelli H. Pregnancy in a rudimentary uterine horn: main clinical forms. 5 cases. Rev Fr Gynecol Obstet. 1994; 89(1): 21-26.

3. O'Leary JL, O'Leary JA. Rudimentary horn pregnancy. Obstet Gynecol 1963; 22: 371 -375.

4. Patra S, Puri M, Trivedi SS, Yadav R, Bali J. Unruptured term pregnancy with a live fetus with placenta percreta in a non-communicating rudimentary horn. Congenit Anom (Kyoto). 2007; 47(4): 156-157.

5. Goel P, Saha PK, Mehra R, Huria A. Unruptured postdated pregnancy with a live fetus in a noncommunicating rudimentary horn. Indian J Med Sci. 2007; 61 (1): 23-27. 